\title{
Consumer properties of potatoes districted in the Moscow region
}

\author{
Anna Vasyukova ${ }^{1 *}$, Alexandr Moshkin ${ }^{1}$, and Tanzila Lubetskaya ${ }^{2}$ \\ ${ }^{1}$ Federal State Budget Educational Institution of Higher Education K.G. Razumovsky Moscow State \\ University of Technologies and Management (the First Cossack University), 109004, Moscow, \\ Russia \\ ${ }^{2}$ Russian University of Cooperation, 114014, Mytishi, Russia
}

\begin{abstract}
The paper considers the potato cultivars of various starch concentration grown in the central part of the country. The aim of the study is to determine the out-come of the product and the consumer properties of different potato cultivars. The objects of the investigation were the following potato cultivars in the Moscow region.
\end{abstract}

Keywords: potato, consumer properties, nutritional value, technological properties

\section{Introduction}

The provision of the population with high-quality food products should be carried out on the basis of new technologies, rational use of raw materials, mechanization of labor-intensive technological operations, high consumer properties and sanitary and epidemiological safety of the final product. In the technically developed countries, potato products are sold to the population, as a rule, in the form of semi-finished products of varying degrees of readiness, requiring simple technological methods with minimal labor costs. The efficiency of the applied technologies is due to the high quality of the products and the ultimate utilization of raw materials. At present, plant breeders have grown about 4,000 varieties of potatoes, and this work continues [1].

Potato is one of the most important plant foods. In the world production of plant food, potatoes occupy the fourth place and are cultivated in more than 130 countries of the world, the annual potato harvest is about 300 million tons. The Russian Federation accounts for more than $10 \%$ of the world gross potato production $[3,4,5]$.

A decrease in the share of the production of commercial potatoes leads to a decrease in the commercial quality and competitiveness of domestic potatoes. In addition, due to the constant increase in electricity prices, the actual volumes of potato processing turned out to be significantly lower than it had been expected. In this regard, the amount of potato losses at all stages of its movement to the consumer in the next period of time will not change significantly. Therefore, the problem of reducing losses and preserving consumer properties is of great importance.

\footnotetext{
* Corresponding author: Vasyukova-AT@yandex.ru
} 
To successfully solve this problem, we need to formulate the consumer properties of potatoes at the growing stage and create all the necessary conditions for their preservation in the process of transportation, storage and sale of products. Only when grown from healthy, virus-free seed material of recoverable varieties, adapted to specific soil and climatic conditions, in compliance with the requirements of agricultural technology, can you get highquality commercial potatoes, reduce losses from microbiological diseases, aging, germination and also to maximize its nutritional value.

In this regard, the improvement of the quality of potatoes is considered as an accumulation of positive properties (food components) during the production period and the achievement of the higher level of the content of these components over a long-term cultivation period.

In recent years, the starch content of potatoes has decreased, $50 \%$ of the produced potatoes do not meet the requirements of standards, $25-60 \%$ of tubers contain toxic substances (pesticides, heavy metal salts, nitrates, etc.) above the permissible levels [2]. The country's crop production is under the constant negative influence of abiotic environmental factors. As a result of stress effects caused by sharp fluctuations in weather conditions, global warming and the action of a complex of anthropogenic factors, there is a decrease in yield, keeping quality and nutritional value of crop products $[6,7]$.

The aim of the research is to determine the yield of semi-finished products and consumer properties of various potato cultivars.

Based on the foregoing, it is necessary to consider the consumer properties of potatoes and the storage potential as a result of the complex interaction of many factors in the agroecosystem.

\section{Materials and methods}

Spot samples were taken from lots of unpackaged potatoes from different places of the embankment in accordance with GOST 33996-2016 Seed potatoes. Technical conditions and methods for determining quality. The size of tubers of the combined sample was measured by the largest transverse and longitudinal diameter using calibration templates and other measuring instruments in accordance with GOST 33996-2016. The assessment of keeping capacity was carried out according to the VNIIKH method, which is based on the laying of tubers by weight for storage and accounting for waste after it. Determination of starch-la content in potato tubers was carried out in accordance with GOST 7194-81. Fresh potatoes. Acceptance rules and quality determination methods. The amount of water was investigated according to ISO 760-78 "Determination of water by the Karl Fischer method (general method)", the mass fraction of protein - by the Kjeldahl method.

\section{Development stages of design and technological solutions}

To identify the optimal consumer characteristics of potato cultivars, we ranked them according to the degree of maturity.

The variety "Shukovsky Early" - early ripening (45-50 days), common usage.

Cultivar description: ultra-early ripening, common usage. The bush is sprawling, of medium height. Stems are few in number, strongly branched. The leaves are large, strongly dissected, dark green, slightly pubescent, with sharp venation. Abundant flowering, shortterm. The inflorescence is compact, multi-flowered. Corolla reddish purple with white tips. Berry formation is absent. Tubers are short-oval with a blunt apex and a flat stolon track, pink to red. The eyes are few and small. The pulp is white, it does not darken when cut.

Characteristics of the cultivar: in the Central region, the yield is $145-324 \mathrm{c} / \mathrm{ha}$. The maximum yield (380 c / ha) was formed in the Lipetsk region. Potential yield - $600 \mathrm{c} / \mathrm{ha}$. 
The mass of the marketable tuber is $122-167 \mathrm{~g}$. The starch con-tent is $10.8-14.7 \%$. The taste is good. Indicators during storage are $92-96 \%$. The resistance of tubers to mechanical damage is $90 \%$. Resistant to cancer and potato nematode.

Cultivar value: resistance to nematode, high early yield with good taste, resistance of tubers to mechanical damage and excellent storage performance.

Variety «Meteor» - very early maturing (55-65 days), for common consumption.

Cultivar description: Bush of medium height, intermediate type. The leaves are green, medium-intensive, medium-sized, moderately dissected. The flowers are white. Tubers are yellow, oval-round. The pulp is yellow, does not darken. The taste is good, crumbly when cooked. The mass of tubers is $130-150 \mathrm{~g}$. The yield is high, $46 \mathrm{~g} / \mathrm{ha}$. Starch content is $10-$ $12 \%$. The shelf life is excellent.

Characteristics of the cultivar: The variety is resistant to cancer, potato nematodes, late blight. It is weakly affected by common scab and rhizoctonia.

Cultivar value: very early ripening, tubers are aligned in size, high palatability, disease resistance.

Variety "Red Scarlett" - early maturing (55-65 days), common purpose.

Cultivar description: plant is low, intermediate type, semi-upright-standing. The leaf is green. The leaf is medium in size. The waviness of the edge is weak. Corolla is medium in size, reddish purple. The tuber is long and oval, with small eyes. The peel is red. The pulp is yellow. The mass of the commercial tuber is $56-102 \mathrm{~g}$. The starch content is $10.1-15.6 \%$. The taste is good.

Characteristics of the cultivar: marketable yield 164-192 c / ha, 22-106 c / ha higher than the standards of «Luck» and "Shukovsky Early" (early). It actively forms tubers together. Productivity on the 45th day after full germination (first digging) - $84 \mathrm{c} /$ ha, $24 \mathrm{c} /$ ha higher than the standard of "Shukovsky Early" (early), on the 55th day (second digging) - $108 \mathrm{c} /$ ha, $45 \mathrm{c} /$ ha above the standard. The maximum yield is $270 \mathrm{~kg} /$ ha. Marketability $82-96 \%$, at the level of the standards. Keeping quality is $98 \%$. Resistant to the causative agent of potato cancer, golden potato cyst nematode. It is susceptible to late blight pathogen in tops and moderately susceptible to tubers.

Cultivar value: nematode resistance, active outcome of early production, high marketability and keeping quality of tubers.

"Snegir" variety - early ripe (65-80 days), common usage.

Cultivar description: plant of medium height, intermediate type, upright or semi-upright. The leaf is large, of medium green color, the waviness of the edge is absent or very weak. Flowering is short-term. The flowers are medium in size, reddish purple with a white tip.

Characteristics of the cultivar: marketable yield 180-271 c/ ha. It forms tubers together. The maximum yield is $354 \mathrm{c} /$ ha. The tuber is round or short and oval, the eyes are small. The peel is smooth to medium, red. The pulp is white. The average number of tubers per bush is $11-15$ pieces. Marketability is $85-90 \%$. The mass of the marketable tuber is $60-90 \mathrm{~g}$. The starch content is $15.7-16.0 \%$ up to $20 \%$. The taste is excellent, boiled semi-crumbly. Keeping quality is $95 \%$. It is resistant to potato cancer.

Cultivar value: high yield, early maturity, formation of early production, high taste of tubers.

Variety «Luck» - early ripening (65-80 days), common purpose.

Cultivar description: early sowing, suitable for summer consumption and winter storage, common purpose. The potato bush is sprawling, low, with a lot of foliage and white inflorescences. The tubers are oval, large, with a thin smooth skin and small eyes. The mass of ripe potatoes is about $100 \mathrm{~g}$. The pulp is white, the starch content is $12 \%$ of the mass of potatoes. 
Characteristics of the cultivar: yield is $1500 \mathrm{~kg}$ per 1 ha. The high content of starch and vitamin $\mathrm{C}$ makes this potato variety suitable for use in many economic purposes, in food and industrial activities.

Cultivar value: it is drought-resistant, high-yielding and early ripe (the har-vest can be dug in June if potatoes are planted with seedlings), does not darken when mechanically damaged. Easily tolerates cold snaps (potato safety - 98\%). Potatoes are resistant to many viral diseases, late blight, cancer, rhizoctonia, rot, wrinkled mosaic, and even the Colorado potato beetle.

"Elizabeth" variety is a mid-early common cultivar.

Cultivar description: refers to medium-early common cultivars of high yields. The cultivar is versatile and adapts well to various climatic conditions. Ripening of tubers occurs within 65-80 days after planting. You can dig potatoes for testing in 50-55 days.

Characteristics of the cultivar: the color of the shell is white, the color of the pulp is the same. The starch content is in the range of 80-140 g. Under good growing conditions, you can easily get up to 10 tubers from 1 pile weighing $80-140 \mathrm{~g}$. The yield of "Shukovsky Early" is up to 400 centners from 1 hectare.

Cultivar value: tubers have good commercial qualities. They have excellent taste, appearance, shelf life (up to 93\%). Also, potatoes do not change their color during heat treatment or after peeling. The variety has a fairly good resistance to late blight of tops and tubers.

"Nevsky" variety - mid-early (80-90 days), common.

Cultivar description: mid-early common high-yielding cultivar with high marketability and excellent taste. The bush is low, compact, upright, with numerous strongly branching stems, white flowers. Tubers are round and oval in shape, with red eyes and an oval top. The peel is white, the flesh is white, does not darken during cutting, the starch content is 10.7$14.8 \%$. The mass of the marketable tuber is $90-130 \mathrm{~g}$. It is easy to wash and clean. They do not crumble during cooking. It is not recommended for frying and mashed potatoes, better in soup and salads. The tubers are well preserved.

Characteristics of the cultivar: marketability - 90-95\%, yield - 38-50 t / ha. Potential productivity is up to $1.5 \mathrm{~kg}$ per bush. The variety is resistant to rhizoctonia, moderately resistant to late blight, common scab. Resistant to drought and waterlogging. The percentage of preservation during winter storage is good. Cultivar of intensive type, actively responds to the application of increased doses of fertilizers. It dislikes cold soils and reacts negatively to cutting tubers and breaking off sprouts. It gives good results when germinating and warming up.

Cultivar value: resistant to cancer, rhizoctonia, early blight and blackened stem, high yield, excellent ecological plasticity, high storage quality, good taste.

Variety «Yabinnyushka» - mid-early (80-90 days), common purpose.

Cultivar description: medium to tall plant, intermediate type, semi-upright. Medium to large leaf, of dark green color. The waviness of the edge is medium. The tuber is oval with small eyes. The peel is smooth and red. The pulp is creamy, does not darken when cut. Marketable yield is 220-234 c / ha (at the level of the standard of «Nevsky»). The maximum yield is $396 \mathrm{c} / \mathrm{ha}, 143 \mathrm{c} /$ ha higher than the standard.

Characteristics of the cultivar: marketable yield is $220-234 \mathrm{~kg} /$ ha (at the level of the standard of «Nevsky»). The maximum yield is $396 \mathrm{c} / \mathrm{ha}, 143 \mathrm{c} /$ ha higher than the standard (Moscow region). The mass of the marketable tuber is 91-133 g. The starch content is 11.9$18 \%$. The taste is good. Marketability is $86-96 \%$. Keeping capacity is $90 \%$. Resistant to the causative agent of potato cancer and golden potato cyst nematode. According to the AllRussian Research Institute of Phytopathology, it is moderately susceptible in terms of tops and moderately resistant in terms of tubers to the causative agent of late blight. 
Cultivar value: high yield and marketability, good taste, resistance to golden potato nematode, excellent storage.

«Lugovoi» variety - middle-ripening (80-100 days), common usage.

Cultivar description: a bush is upright, compact and of medium height. A leaf is medium, dissected and pubescent. Flowering is average, short-term. The inflorescence is compact and multi-flowered. Berry formation is rare. The tuber is oval, with a blunt apex and a flat stolon trace, light pink. The peel is smooth. The eyes are few and small. The pulp is white, does not darken when cut.

Characteristics of the cultivar: the cultivar is high-yielding - 51.4 t / ha in the State test. The marketability of tubers is high with good keeping quality. The mass of the marketable tuber is $83-165 \mathrm{~g}$. The starch content is $12-19 \%$, the taste is good and excellent. It is resistant to cancer, relatively resistant to late blight, common scab, moderately resistant to viruses and damping out.

Cultivar value: high yield, excellent taste, high storage quality, high market-ability.

Variety "Holubyzna"- mid-season (80-100 days), for common use.

Cultivar description: bush is of medium height, semi-spreading and has dark green leaves. The flowers are blue-violet with white tips. Tubers are white, rounded, with a blunt top. The peel is mesh. Eyes are small to medium. The pulp is white, does not darken during cooking. The taste is excellent, friable when cooking. Tuber mass is 100-150 g. High-yielding, up to 50 tons and more per hectare. Starch content is $18-21 \%$, dry matter - up to $26 \%$, high yield marketability - up to $97 \%$

Cultivar characteristics: the cultivar is resistant to cancer, ring and wet rot, scab, rhizoctonia, early blight, $\mathrm{Y}$ virus, relatively resistant to other potato mosaic viruses. Medium resistant to phytofluorosis. It is resistant to drought and heat. The yield is good when there is little rainfall. In some years, hollowness is possible, it requires a thickened planting. It shows resistance to low temperatures.

Cultivar value: excellent taste, resistant to many diseases, good keeping quality of tubers.

Variety «Resource» - mid-season (90-100 days), common usage.

Cultivar description: light beige tubers. The eyes are small. The pulp is white. The corolla is white. Productivity is $40-45 \mathrm{t} /$ ha. Marketability is $85-94 \%$. The mass of the marketable tuber is $100-130 \mathrm{~g}$. Starch content is $13-16 \%$. The taste is good and excellent. The tubers are well preserved.

Cultivar characteristic: resistant to viruses $\mathrm{X}$ and $\mathrm{Y}$, early blight, heat, drought. It is medium resistant to late blight in tops and tubers, to common scab. Rhizoctonia is poorly affected.

Cultivar value: excellent taste, high yield and marketability, resistant to viral diseases, heat, drought, excellent storage.

Variety «Victory» - mid-late (110-120 days), common usage.

Cultivar description: plant is tall, of leaf type, upright. Medium-sized leaf, light green. Corolla is medium in size, reddish purple. Marketable yield is 191-304 c / ha, at the level and $77 \mathrm{c} /$ ha higher than the standard of "Shukovsky Early".

Cultivar characteristic: oval-rounded tuber with small eyes. The peel is smooth, yellow. The pulp is white. The mass of the commercial tuber is 78-158 g. The starch content is 10.3$13.2 \%$. The taste is good. Marketability $-84-98 \%$. Keeping quality is $91 \%$. Resistant to the causative agent of potato cancer, susceptible to the golden potato cyst nematode, moderately susceptible to the causative agent of late blight in the tops and tubers.

Cultivar value: stable yield, uniformity, drought resistance and heat resistance.

The results of the research are presented in the table 1 and 2.

A deeper study of the ways of forming the consumer properties of potatoes at all stages of commodity circulation is facilitated by complex and multilateral studies conducted with samples of potato cultivars "Nevsky", «Lugovoi», «Luck», «Victory», "Elizabeth", "Snegir", 
«Yabinnyushka», "Red Scarlett" and "Shukovsky Early". The research results are shown in Table 1 and 2.

As a result of the research, it was found that the largest tubers in size are «Luck», "Snegir" and "Red Scarlett" (75-85 mm), while the smallest one is "Elizabeth" (35 mm). But in terms of weight «Yabinnyushka» (126 g), «Luck» (114 g) and «Victory» (106 g) are classified as large, while "Shukovsky Early" (72 g) and "Nevsky" (76 g) are the smallest.

Table 1. Weight-size characteristics of potato tubers and waste in processing

\begin{tabular}{|c|c|c|c|c|c|c|}
\hline \multirow{2}{*}{$\begin{array}{l}\text { Variety } \\
\text { Potato }\end{array}$} & \multicolumn{3}{|c|}{ Dimensions } & \multirow[b]{2}{*}{$\begin{array}{l}\text { The weight } \\
\text { of the } \\
\text { tubers, mr. }\end{array}$} & \multirow{2}{*}{$\begin{array}{c}\text { Weight of } \\
\text { semi- } \\
\text { finished, } \\
\text { mr. }\end{array}$} & \multirow[b]{2}{*}{$\begin{array}{c}\text { Waste during } \\
\text { cleaning, } \mathbf{g}, \\
(\%)\end{array}$} \\
\hline & $\begin{array}{l}\text { length, } \\
\text { mm }\end{array}$ & $\begin{array}{l}\text { height, } \\
\text { mm }\end{array}$ & $\begin{array}{l}\text { width, } \\
\text { mm }\end{array}$ & & & \\
\hline Elizabeth & 35 & 35 & 45 & 88 & 80 & $8 \quad(9,1)$ \\
\hline Bullfinch & 75 & 33 & 52 & 96 & 88 & $8 \quad(8,33)$ \\
\hline Luck & 85 & 30 & 52 & 114 & 103 & $11(9,64)$ \\
\hline Rowan & 67 & 40 & 62 & 126 & 113 & $13(10,31)$ \\
\hline Red lady & 75 & 33 & 48 & 86 & 77 & $9(10,46)$ \\
\hline Victory & 60 & 40 & 60 & 106 & 97 & $9 \quad(8,49)$ \\
\hline Nevsky & 40 & 30 & 30 & 76 & 68 & $8 \quad(10,52)$ \\
\hline Lugovskaya & 53 & 35 & 40 & 82 & 72 & $10 \quad(12,2)$ \\
\hline Schukovsky & 60 & 35 & 50 & 72 & 62 & $10 \quad(13,9)$ \\
\hline
\end{tabular}

Table 2. Nutritional value of experienced potato varieties

\begin{tabular}{|l|c|c|c|c|c|}
\hline $\begin{array}{c}\text { Variety } \\
\text { Potato }\end{array}$ & $\begin{array}{c}\text { Water, } \\
\mathbf{\%}\end{array}$ & $\begin{array}{c}\text { Proteins, } \\
\mathbf{\%}\end{array}$ & $\begin{array}{c}\text { Starch, } \\
\mathbf{\%}\end{array}$ & Sahara, \% & Calories, kcal \\
\hline Elizabeth & 78,6 & 2,0 & $13,0-18,0$ & 0,1 & 77 \\
\hline Bullfinch & 75,6 & 2,0 & $16,0-20,0$ & 1,0 & 77 \\
\hline Luck & 79,7 & 2,0 & $11,0-14,5$ & 1,3 & 77 \\
\hline Rowan & 77,2 & 2,0 & $11,9-18,0$ & 0,31 & 84 \\
\hline Red lady & 77,7 & 2,0 & $12,5-16,8$ & 1,0 & 83 \\
\hline Victory & 81,3 & 2,0 & $10,3-13,2$ & 1,0 & 70 \\
\hline Nevsky & 79,0 & 2,0 & $10,1-15,6$ & 1,0 & 77 \\
\hline Lugovskaya & 81,8 & 1,89 & $12,0-12,5$ & 1,3 & 70 \\
\hline Schukovsky & 84,0 & 1,9 & $9,5-10,1$ & 1,0 & 70 \\
\hline
\end{tabular}

While preparing semi-finished products, it was found that the minimum amount of wastes was obtained when peeling potato cultivars "Snegir" (8.33\%), «Victory» (8.49\%) and "Elizabeth" (9.1\%). And since the research was carried out in April, compared to the Norms of waste and losses during processing of food products, the wastes obtained during potato peeling is 5 times less than these norms. This indicates the high-quality storage of potatoes for such a long period of time.

Starch is the main potato component. Thanks to it, the vegetable gets energy value. In order not to spoil the dish, it is important to know which potato cultivars can be recommended for various dishes. With different concentration of starch in a tuber, its properties are differentiated: it is enough to cut a potato and rub the halves. Agglutination will indicate high starchiness, while the presence of liquid will speak about low content of starch. Competent selection of the appropriate potato cultivar, as well as the use of the optimal amount per serving will make the nutrition balanced and the culinary process is not complicated.

We have also analyzed the situation in the development of the food potato market and studied the factors that form the consumer properties of the product; the consumer and 
technological properties of economic and botanical potato cultivars have been investigated and an assessment of their competitiveness is given $[8,9,10]$.

\section{Conclusion}

Thus, a comprehensive assessment of the nutritional value, organoleptic and technological properties of promising economic and botanical potato cultivars grown in various soil and climatic conditions of the Moscow region showed that:

Cultivars "Snegir" and "Red Scarlett" differ in higher level of accumulation of the main nutritional components and high organoleptic and technological properties;

Cultivar «Luck» demonstrates high crop capacity, but differs in worse technological properties and keeping capacity;

Cultivars "Snegir", "Elizabeth" and «Victory» are characterized with stable physiological processes at long storage that is resulted in their better keeping capacity;

Cultivars "Snegir", "Red Scarlett" and "Nevsky" demonstrate high marketability and keeping capacity, they are resistant to different diseases.

In terms of usage cultivars with high starch content can be divided into the following groups:

-universal potato is similarly suitable both to consumption and to production of starch and other substances;

-commodity potato is grown in huge amounts as it is used for sale, the starch content of this potato corresponds to the botanical potato cultivar;

-commercial potato is used for production of alcohol and starch, feeding of animals;

-feed potato differs in higher concentration of both starch and protein that makes it better than commercial potato.

\section{References}

1. Belenkov A.I. 2011. Results of field experience of the Center of accurate agriculture in different agrometeorological conditions. Adaptation of agriculture in Russia to the changing climate conditions. International Conference. RSAU - MSAA named after K.A. Timiryazev, 14-16 December 2010, p. 140-147

2. N.N. Lipatov Zelenyi mir. 4 (1995)

3. Yu.V. Moiseev, B.V. Anisimov, Agroinform Analysis 1 (2000)

4. E.V.Shein, A.G. Bondarev, Agrophysics of soils. (MSU Publishing House, Moscow, 2005)

5. Shpaar D. (ed.) Precise agriculture (Pushkin Publishing House, St. Petersburg, 2009)

6. Temirbekowa S.K. Evalution of cereal crops gene peol for EMES (enzyme-mucotic exhaustion of Seeds) resistance during mucotic stage // Tours. 3-4-5 December. 1997. Fifth Conference Internationale Sur: des maladies des plantes, France.

7. Ya.D. Van Mansvelt, S.K. Temirbekova Reports of RAS of Agriculture, 5 (1999)

8. Vasyukova A.T., Yarosheva A.I., Moshkin A.V. 2016. Present danger - chemical pollution of food / Proceedings of the Ist International Scientific Conference with the elements of Scientific School for Youth. M.: Institute of Technologies and Business of the Moscow State University of Technologies and Management named after K.G. Razumovskiy. p. 89-93

9. A.T. Vasyukova, A.V. Moshkin, A.I. Yarosheva, I.A. Fedorkina Agroindustrial technologies of the Central Russia 3, 3 (2017)

10. V.V.Yakushev, V.V.Voropaev, P.V. Lekomtsev Resource saving agriculture, 2 (2009) 